\title{
The Development of Intercultural Sensitivity of Business English Majors by the Multimodal Teaching Program*
}

\author{
Xin Yang \\ School of Foreign Languages, Sichuan University of Arts and Science, Dazhou, Sichuan, China
}

\begin{abstract}
This study is to empirically investigate the effect of the multimodal teaching program in developing Chinese learners' intercultural sensitivity. This experiment was carried out among 31 business English majors from a local university in Southwest China within one semester. The findings indicated that the participants showed a great improvement in their general level of intercultural sensitivity, and it is worth mentioning that among the factors of intercultural sensitivity, interaction confidence and attentiveness have witnessed a greater progress than the other factors.
\end{abstract}

Index Terms - intercultural sensitivity, business English majors, multimodal teaching

\section{INTRODUCTION}

Foreign language learning is inseparable with cultural factors, and correspondingly intercultural communicative competence (ICC) has become the focus in foreign language teaching. Since for a long time, researchers have tried to cultivate learners' ICC from the three aspects: the cognitive, the affective and the behavioral aspect (Chen and Starosta, 1996; Byram, 1997). And among them, one of the most influential approaches is to develop learners' intercultural sensitivity from the affective perspective, which is regarded as the prerequisite of the development of ICC.

The multimodal teaching is to arouse learners' curiosity, motivation and attention by decoding the meanings conveyed by the multiple media, like sounds, videos, three-digital animations as well as words (Halliday, 2000; Kress and van Leenwee, 2006). While applied in cultural teaching and learning, it can help foreign language learners have a better understanding and appreciating of the cultural differences, which can reduce the negative effect of the traditional teaching by just feeding learners on the cultural knowledge. This study, based on the previous ones, is a mixed investigation into the effect of the multimodal teaching program on Chinese learners' intercultural sensitivity in learning the comprehensive business English course.

\section{THEORETICAL FOUNDATION}

\section{A. Intercultural Communicative Competence and Intercultural Sensitivity}

Intercultural communicative competence has always been a hot topic in intercultural communication research, but till now, there is still no widely accepted definition for it. Byram (1997) proposed that ICC consists of linguistic competence, sociolinguistic competence, discourse competence and intercultural competence. In other words, it covers the knowledge about language and its culture, the skill to communicate with people from other cultures properly, and the attitude toward other cultures and the intercultural awareness. Another influential model of ICC is put forward by Deardorff (2006), who believed that ICC includes three layers of competence. The first is the essential part: respect, open-mindedness, and curiosity; the second is the necessary knowledge and skill; the third includes the adaptability, flexibility, ethnorelativism and empathy. It can be concluded that ICC requires linguistic and cultural knowledge, sensitivity to cultural diversities, tolerance of different cultures, respect for other cultures and skills to maintain proper interpersonal relationship. Though expressed in different ways by different researchers, ICC can be found to be composed of three aspects: the cognitive ability, emphasizing the basic knowledge and understanding of culture; the affective ability, emphasizing the attitude and the emotion in the intercultural communication process; the behavioral ability, meaning the skill or the strategy in achieving successful intercultural communication.

Intercultural sensitivity is "an individual's ability to develop a positive emotion towards understanding and appreciating cultural differences that promotes an appropriate and effective behavior in intercultural communication" (Chen, 1997). From the definition, it can be inferred that intercultural sensitivity focuses on the affective aspect of ICC, which can be further divided into six parts: self-esteem, self-measuring, open-mindedness, empathy, interaction involvement and non-judgment (Chen and Starosta, 1996). People with higher self-esteem can be more positive in intercultural communication so that they feel less depressed and stressed. A strong self-monitoring ability can enable

\footnotetext{
**This is a paper supported by Higher Education Research Project of Sichuan University of Arts and Science, Grant No. 2015GJ004Z.
} 
one to be more attentive and more sensitive to others' expressions so as to adjust one's own behavior more properly. Open-minded persons are willing to show their own feelings and to be open to others' ideas, requirements and differences. Empathy is the ability to put oneself in others' shoes to understand their opinions and emotions. The higher interaction involvement indicates that the communicator can have a better insight into others' message and make a proper response, while non-judgment means listening to others sincerely instead of making judgment bluntly so as to get more joy in communication.

From the above analysis, we can see that ICC is a cover term, and intercultural sensitivity is one component of it. As an affective factor, intercultural sensitivity is the precondition of the development of the cognitive ability in ICC, influencing the communicator's willingness to understand and learn the exotic cultural knowledge. It also plays a critical role in the behavioral ability in ICC, which decides how a communicator behaves in the intercultural communication. Successful intercultural communication is achieved by communicators' ability of intercultural awareness and the behavioral effectiveness and appropriateness enhanced by intercultural sensitivity (Chen and Starosta, 2000).

\section{B. The Researches of Intercultural Sensitivity}

Intercultural sensitivity has aroused many researchers' attention, and the earlier pioneer studies mainly investigated its importance in ICC (Brislin, Cushner, Cherri and Yong, 1986; Gudykunst, Guzley and Hammer, 1996). The later researches approached it mainly from two aspects. Some intended to find out the factors influencing intercultural sensitivity, like Anderson, Lawton and Rexeisen, ect. (2006). They found that the short-term overseas experience can improve the communicators' intercultural sensitivity. Mahoney and Sehamber (2004) indicated that different courses can influence the improvement of intercultural sensitivity. Holm's study showed that the gender and academic achievement are related with intercultural sensitivity, while the female learners have a better intercultural sensitivity (2009). Other studies were devoted to the experimental studies of the intercultural sensitivity training. Rahimi and Soltani (2011) tried to find out the teachability of Iranians' intercultural sensitivity from the perspective of ethnocentrism and ethnorelativism. Jain (2013) used intercultural films and discussions to train students' intercultural sensitivity. Tupas (2014) proposed that only deliberate and carefully planned program by the teacher can help with the development of intercultural sensitivity. Nick, Hofstede and Beulens, ect.(2016) used some digital intercultural tools to train and improve the participants' intercultural sensitivity.

\section{Research Statement and Questions}

Benett (2004) has emphasized that intercultural sensitivity develops based on one's experience, instead of the sole inputting of linguistic and cultural knowledge. For most Chinese learners, English is the foreign language for them to learn in schools, but there are not so many opportunities for them to contact with the English-speaking natives and to be immersed in the culture, which results in a slow development in their cultural awareness and ICC. However, in the multimodal teaching program, learners can be stimulated to observe, compare and reflect on the cultural differences in a more direct way, since the multimodal way of teaching can help with the creation of an exotic environment by using different static resources like costumes and colors, and the dynamic resources like language, sounds, facial expressions and gestures. It is believed that multimodal teaching can serve as a bridge of the learners' existing knowledge and the new knowledge. Based on their own experience, learners can be motivated to participate in the learning process and explore the exotic language not only by the written words but also by the multimodal message received by listening, seeing and touching (Zhang, 2009).

Given the beneficial effect of the multimodal teaching, this research is to design a case study of its use in a comprehensive business English course by investigating 31 subjects' development of intercultural sensitivity in one semester, which is to indicate the effectiveness of the multimodal teaching in cultivating Chinese learners' intercultural sensitivity. Therefore, this study intends to answer the following two questions:

1. Can learners' intercultural sensitivity be improved through the multimodal teaching program?

2. What are the effects of the multimodal teaching in developing learners' intercultural sensitivity?

\section{Methodology}

\section{A. Participants}

This research involved 31 participants who were first-grade business English majors all from the same class in a local university in Southwest China. Before the experiment, they were told that they would be in an experimental class for one semester which aimed to help them with the difficulties in intercultural communication, and all of them agreed to participate in the experiment at the very beginning and remained in the class until the whole course was completed.

\section{B. Materials and Instruments}

In order to compare the effect of the multimodal teaching program, intercultural sensitivity scale (ISS) proposed by Chen and Starosta(2000) was adopted to test the learners' level of intercultural sensitivity before and after the experiment. The scale is composed of 24 five-point Likert items covering the five factors of intercultural sensitivity: Item 1, 11, 13, 21, 22, 23 and 24 are about interaction engagement; Item 2, 7, 8, 16, 18 and 20 are about respect for 
cultural differences; Item 3, 4, 5, 6, and 10 about interaction confidence; Item 9, 12 and 15 are about interaction enjoyment; Item 14, 17, and 19 about interaction attentiveness. Each item gives a five-point rating scale ranging from 1 to 5: 1 means strongly disagree, 2 disagree, 3 not sure, 4 agree and 5 strongly agree. The validity and reliability of this scale has been proved by Fritz, Mollenberg and Chen (2001), and Cronbach alpha coefficient was 0.78. The teaching materials are based on the teaching textbooks, supported by video clips chosen from the Internet.

\section{Procedure}

Before and after the experimental class, a survey was made to look into the participants' intercultural sensitivity respectively, and all the participants were required to finish a questionnaire of ISS within 30 minutes.

During the one semester's course, the participants were assigned six tasks to finish within 12 weeks. Before each task, the teacher would give them the topic for the following class and the reading materials with questions. In the class, the participants would be checked about their answers to the questions of the reading material, for which the teacher did not give any direct comment. Then they would be shown one or two pieces of videos about 8-10 minutes, and after watching, they were required to find out the proofs to support their previous answers. They discussed in groups about the language use, the body movement, facial expressions and other non-verb information signs. The teacher was just a guide, a helper and a coordinator in the process. When the 20 minutes' discussion was done, each group would send a representative to present their findings and for each task, they should choose a different presenter. Followed each group's presentation, there would be questions from other groups. After class, the subjects need to reflect on what they had learned in class in writing forms to reinforce their learning results.

After the six tasks were completed, 20 participants were chosen randomly to make an evaluation of the class and to answer the researcher's questions about the effect of the multimodal teaching program.

\section{Data Collection and Analysis}

The researcher and teacher carried out the investigation herself. Before the implementation of the questionnaire, instructions and explanations were given to make sure that all the participants understand the requirement and each item well. Thanks to the participants' cooperation, for both the pre-experimental and the post-experimental investigation, 31 valid questionnaires were collected.

In order to make the result more objective, we adopted Statistical Packages for Social Science (SPSS) version 18.0 to analyze the quantitative data collected in this research, the result of which can show us the changes of the intercultural sensitivity of the participants before and after the experiment.

\section{RESUlts}

\section{A. The Pre-experimental Intercultural Sensitivity}

With the data collected and analyzed, we got the following descriptive statistics about the participants' intercultural sensitivity before the experiment as listed in Table I. From the table, we can see that the mean total score of the participants' intercultural sensitivity is 80.89 , which is not so high, since the full mark is 120 . It can be inferred that there is still a large room for these learners to improve themselves. As for the level of respect for cultural differences, it ranks the highest among the five factors with a mean score of 3.56, which means that though these participants had not accepted any special training of intercultural communication, they still had a certain awareness of cultural differences. The mean scores of interaction engagement and enjoyment are 3.42 and 3.36 respectively, while those of interaction confidence and attentiveness are 3.23 and 3.12 respectively. For most of the participants, they rarely had any opportunities to go abroad. Therefore, they did not have enough experiences in the exotic culture and they knew little about the way to communicate with foreigners, which made them lack self-confidence in communicating with foreigners.

TABLE I

DESCRIPTIVE STATISTICS OF THE PRE-EXPERIMENTAL INTERCULTURAL SENSITIVITY

\begin{tabular}{lllll}
\hline \multicolumn{2}{c}{ DESCRIPTIVE STATISTICS OF THE PRE-EXPERIMENTAL INTERCULTURAL SENSITIVITY } \\
\hline Total score & Minimum & Maximum & Mean & Std. Deviation \\
Interaction engagement & 60 & 98 & 80.89 & 8.58 \\
Respect for cultural differences & 2.14 & 4.51 & 3.42 & 0.62 \\
Interaction confidence & 2.89 & 5 & 3.56 & 0.72 \\
Interaction enjoyment & 1.6 & 5 & 3.23 & 0.68 \\
Interaction attentiveness & 2.12 & 4.6 & 3.36 & 0.51 \\
\hline \hline
\end{tabular}

\section{B. The Post-experimental Intercultural Sensitivity}

The mean total score after the experimental class is 93.42 with the maximum score of 112 and the minimum score of 71. In Table II, it can be found that there is a great improvement of the participants' total score compared with that before the experiment. The mean scores for the five factors are 4.21 for respect for cultural differences, 3.92 for interaction engagement, 3.84 for interaction confidence, 3.40 for interaction enjoyment and 3.80 for interaction 
attentiveness, which forms a different rank from the pre-test one. In the rank, respect for cultural differences is followed by interaction engagement, interaction confidence, interaction attentiveness and interaction enjoyment successively. Though respect for cultural differences and interaction engagement remain the first and the second, interaction confidence and attentiveness have made greater progress than interaction enjoyment.

TABLE II

DESCRIPTIVE STATISTICS OF THE POST-EXPERIMENTAL INTERCULTURAL SENSITIVITY

\begin{tabular}{lllll}
\hline \hline & Minimum & Maximum & Mean & Std. Deviation \\
\hline Total score & 71 & 112 & 93.42 & 7.67 \\
Interaction engagement & 3.22 & 5 & 3.92 & 0.46 \\
Respect for cultural differences & 2.6 & 5 & 4.21 & 0.56 \\
Interaction confidence & 2.00 & 5 & 3.84 & 0.60 \\
Interaction enjoyment & 2.41 & 4.6 & 3.40 & 0.54 \\
Interaction attentiveness & 3.17 & 4.8 & 3.80 & 0.51 \\
\hline \hline
\end{tabular}

\section{The Participants' Evaluation of the Experimental Class}

To further prove the effect of the experimental class, we interviewed 20 participants randomly chosen from the sample. All of them took a positive attitude toward the multimodal way of teaching. They said that it was more vivid and interesting than the traditional way of intercultural learning, because in the class they gradually realized that cultural differences could be traced in different forms such as dressing styles, body movements, space between communicators and facial expressions. They also reported that they were not shy to communicate with foreigners anymore, and it was an exciting thing to know the other cultures. 18 of them believed that they could be more tolerant of the cultural differences if there was any and they were willing to understand the other side's feelings. 16 of them claimed that they were not scared to talk with foreigners anymore and knew how to interpret the cultural clues in communication, showing a great confidence in intercultural communication. As for the question how to maintain a hospital and negotiation relation with the foreigner, 16 of them said that eye contacts was important and the pronoun "we" might be a better choice than "I". Five boys said that before the class, they thought learning a foreign language just was a matter of learning the words, grammar and sentences, but after finishing the class, they came to know that it was a matter of learning the culture at the same time. As for the influence of their linguistic proficiency, all of the interviewees thought that their attention tended to be averted to the language itself because of their limited vocabulary and listening comprehension ability. Still one more thing needs to be pointed out: the multimodal teaching program can only create a virtual communicative atmosphere, so the interviewees also reported that they were not sure about their performance in the real intercultural communication.

\section{Discussions}

Based on the analysis of the investigation and interview results, it can be concluded that the multimodal teaching program plays an important role in promoting learners' intercultural sensitivity. By comparing the data in Table I and Table II, we can see that the general level of intercultural sensitivity has been greatly improved, not just including the average score but also the maximum and the minimum scores. According to the interview, all the participants enjoyed the way of teaching and learning, by which they can be fully stimulated and involved in observing and analyzing the cultural differences. And with the group work, they formed a better understanding of those differences. In the multimodal teaching program, the participants may become more critical through complementing the tasks, the group discussions and presentations, because they were not given answers directly but they were encouraged, attracted and guided to find out the answers themselves. It is a kind of learning by discovering, which can promote learners to explore and collaborate with teachers and peers in solving problems. Besides, learners can be more actively involved in the learning process, and correspondingly, learners' motivation can be greatly activated (Carroll and Beman, 2015).

Respect for cultural differences was the first one in the rank of the five factors of intercultural sensitivity even before the experiment, which means that the advancement of the hi-tech does give the learners more access to foreign cultures than before. Therefore, it is not hard for them to identify some cultural differences in intercultural communication. After the experiment, their levels of respect of cultural differences are much higher. They are more open and more tolerant to the other culture, and are more willing to put themselves in the native speaker's position to understand the cultural differences. All of these progresses have to be attributed to the advanced learning technology and the well designed tasks.

The level of interaction engagement has also been improved after the experiment, which means learners are more willing to communicate with foreigners. The multimodal way of teaching can greatly activate the learners' enthusiasm and passion in participating in the activities, because in the learning process, they may find that there are more sources of messages which are worth observing and analyzing than they thought before.

As for the interaction confidence and interaction attentiveness, the learners also made a great progress in these two aspects. In the interview, they seemed to be more confident in deciding on the strategies to effectively communicate with others. Maybe it is because they have learned how to obtain the cultural messages expressed through careful 
observations and analyses, and therefore make proper response. With these abilities, it is natural that these learners have become more confident and observant. However, it is a pity that the participants' interaction enjoyment did not get $g$ great improvement compared with other factors. One reason may be that there learners were freshmen and their language proficiencies were not enough for them to communicate freely in English. Another reason might be that the multimodal way of teaching can create a good intercultural communication environment but it is still not real in nature. So learners could not feel the joy from a successful communication with foreigners by applying what they have acquired in the class.

\section{IMPLICATIONS AND LIMITATION}

Intercultural sensitivity represents the affective aspect of intercultural communicative competence, and it may have some correlation with the other aspects of ICC. Based on the results of this research, it can be inferred that the development of intercultural sensitivity is related with that of learners' cognitive and behavioral ability. The former can reduce the negative influence of low linguistic proficiency and help with the improvement of interaction engagement and attentiveness. The latter can increase learners' interaction enjoyment especially by practicing the knowledge and strategies acquired. Therefore, the training of intercultural sensitivity cannot be isolated from the other aspects, and the development of ICC should combine the linguistic forms and functions, the connotations of culture with the real experience in intercultural communication.

Firstly, encourage learners to make progress by discovery learning. The classroom is where learners are required to develop their communicative ability which in turn can hardly be formed by the passive inputting of knowledge. The multimodal teaching program is one of the teaching methods which can broaden learners' insight into a more colorful world, and stimulate their curiosity to the unknown world. The learners themselves play a more active role in the process, as long as the teacher can find a proper way to arouse their learning interest.

Secondly, create more communicative opportunities for learners. In school, teachers and learners can work together to design various activities for language use. One of the choices might be the building up of a friendly relationship with the overseas students on the campus. It is a win-win activity for both the Chinese learners of English and the overseas students in China, because in the process, the two sides can have a direct contact with and a better understanding of the foreign cultures. It is also suggestive for learners to participate in the society activities in school, like English club, English debates and English plays. In addition, the internet is a huge source where learners can have real experiences and have a lot of fun with foreign cultures, like the on-line chatting apps and the forums of English learning. Only in the real situations can learners develop their empathetic feeling and tolerance of the exotic culture better.

Thirdly, insist on culture teaching through the whole process of language teaching. It is urgent for both teachers and learners to realize that language learning cannot be separated from culture. As also can be found in this research, some learners, while learning a language, just focus on the linguistic form. In the end, they may develop a low level of intercultural communicative competence. So no matter what kind of teaching method is adopted, the teaching process should always adhere to this principle, the principle of culture teaching.

This research is a cross-sectional study of the effect of the multimodal teaching program on Chinese learners' intercultural sensitivity, and inevitably it may suffer from some limitations. Firstly, there is a limitation of time, because the experiment lasted just one semester and we did not have enough time to know the diachronic development of learners' intercultural sensitivity. Secondly, this research did not take into account the correlation between intercultural sensitivity and the language proficiency, so it is not clear whether learners with different levels of language proficiencies may make different degrees of improvements in the multimodal teaching program. Thirdly, the sample of this study is also quite limited and more proofs are needed to further support the teachability of intercultural sensitivity in future.

\section{REFERENCES}

[1] Anderson, P. H., L. Lawton, R. J. Rexeisen \& A. C. Hubbard. (2006). Short-term study abroad and intercultural sensitivity: A pilot study. International Journal of Intercultural Relations 30.4, 457-469.

[2] Bennett, M. J. (2004). Becoming interculturally competent. In J. S. Wurzel (Ed.), Toward multiculturalism: A reader in multicultural education. Newton, MA: Intercultural Resource Corporation, 147-165.

[3] Brislin, R. W., K. Cushner, C. Cherrie \& M.Yong. (1986). Intercultural interactions: A practical guide. Beverly Hills, CA: Sage.

[4] Byram, M. (1997). Teaching and assessing intercultural communicative competence. Clevedon: Multilingual Matters.

[5] Carroll, J., \& V. Beman. (2015). Boys, inquiry learning and the power of choice in middle school English classroom. Adolescent Success 15.1, 4-17.

[6] Chen, G. M. (1997). A review of the concept of intercultural sensitivity. Human Communication 1, 1-16.

[7] Chen, G M. \& W. J. Starosta. (1996). Intercultural communication competence: A synthesis. In B. R. Burleson (Ed.), Communication Yearbook 19, 353-384.

[8] Chen, G. M. \& W. J. Starosta. (2000). The development and validation of the intercultural communication sensitivity scale. Human Communication 3, 1-15.

[9] Deardorff, D.K. (2006). Identification and assessment of intercultural competence as a student outcome of internationalization. Journal of Studies in International Education 1.3, 241-266.

[10] Fritz, W., A. Mollenberg \& G. Chen. (2001). Measuring intercultural sensitivity in different cultural context. Paper presented at 
the Biannual Meeting of the International Association for Intercultural Communication Studies, July 24-29, Hong Kong.

[11] Gudykunst, W. B., R. M. Guzley \& M. R. Hammer. (1996). Designing intercultural training. In D. Landis and R. S. Bhagat (Eds.), Handbook of intercultural training. Thousand Oaks, CA: Sage.

[12] Halliday, M. A. K. (2000). An introduction to funcitonal grammar. Beijing: Foreign Language Teaching and Research Press.

[13] Holm, K. (2009). Relationship of gender and academic achievement to Finnish students' intercultural sensitivity. High Abilities Studies 20.2, 187-200

[14] Jain, S. (2013). Experiential training for enhancing intercultural sensitivity. Journal of Cultural Diversity 20.1, 15-20.

[15] Kress, G. \& T.van Leeuwen. (2006). Reading images: The grammar of visual design (2nd Edition). London: Routledge.

[16] Mahoney, S. L. \& J. F. Sehamber. (2004). Exploring the application of a developmental model of intercultural sensitivity to a general education curriculum on diversity. The Journal of General Education 53.3-4, 311-334.

[17] Nick D., G. J. Hofstede, A. Beulens, E. Krumhuber \& A. Kappas. (2016). Don't be a stranger-designing a digital intercultural sensitivity training tool that is culture general. IEEE Transactions on Learning Technologies 9.2, 120-132.

[18] Oslon, C. L. \& K. R. Kroeger. (2001). Global competency and intercultural sensitivity. Journal of Studies in International Education 5, 116-137.

[19] Rahimi, A. \& A. Soltani. (2011). Teachability of intercultural sensitivity from the perspective of ethnocentrism vs. ethnorelativism: An Iranian experience. Iranian Journal of Applied Linguistics 14.1, 113-139.

[20] Tupas, R. (2014). Intercultural education in everyday practice. Intercultural Education 25.4, 243-254.

[21] Zhang, D. L. (2009). Multimodal discourse theory and its application to foreign language teaching with modern media technology. Foreign Language Education 4, 15-20.

Xin Yang was born in Sichuan, China in 1981. She got her MA in Southwest University in China, majoring in Foreign Linguistics and Applied Linguistics. She is currently a lecturer in the School of Foreign Languages, Sichuan University of Arts and Science, Sichuan, China. Her research interests include Second Language Acquisition and Foreign Language Teaching. 